\title{
The ethics of resource allocation
}

Proceedings of a symposium held at the University of Manchester during the 33rd Annual Scientific Meeting of the Society for Social Medicine, September 1989.

\begin{abstract}
Alwyn Smith
It would make no sense at all to distribute available health and medical care equally among the population: the needs of individuals vary and are quite specific to each. Three different principles might be used to guide the distribution of such care: (1) distribution according to individual willingness and ability to meet the cost; (2) distribution in accordance with individual need; (3) distribution so as to maximise the total surplus of benefit over cost.
\end{abstract}

DISTRIBUTION ACCORDING TO INDIVIDUAL WILLINGNESS AND ABILITY TO MEET THE COST This is the principle of simple marketing. It is an acceptable principle for the distribution of a commodity in certain circumstances: (a) when the commodity is of trivial consequence; (b) when the supply is adequate to meet all demand; (c) when all individuals have the wherewithall to meet their needs for the commodity; (d) where unequal distribution of the commodity may be justified in the interests of either rewarding differing degrees of contribution made to the general good or of driving a competitive economy so as to maximise the product available for distribution.

Most people would find it difficult to justify regarding health and medical care as a commodity fulfilling these requirements.

DISTRIBUTION IN ACCORDANCE WITH INDIVIDUAL NEED

This raises both the difficulties of defining and measuring need and the problems of managing the allocation and distribution of the quite complex resources that comprise health and medical care-including the work of many different professions, the materials deplnyed in their practices and the premises in which they function.

An issue of fundamental importance is whether individuals may be held to need anything from which they cannot demonstrably benefit. A further complication of this issue arises in the attempted commensuration of the different kinds of needs experienced by different individuals with different illnesses or disabilities.

DISTRIBUTION SO AS TO MAXIMISE THE TOTAL SURPLUS OF BENEFIT OVER COST

This assumes not only that individuals' needs may be subordinate to the public good but also that it is possible to commensurate benefits and costs over the whole range of health care inputs and outputs.
The QALY represents a first attempt to quantify the outcomes of health care investment by combining in a life table analysis the duration of associated survival with a factor representing the concomitant impairment of survival quality. The most intractable methodological difficulty of this approach is that of ensuring that the factors needed for estimating quality are reciprocally commensurable with duration of survival. This problem seems to have received little attention.

The debate resolves essentially into whether health and medical care should be used primarily to reduce health variance or to increase its mean. Is it to be viewed as contributing to the economic output of the nation or as part of the apparatus of social justice? These are essentially political questions as much as ethical ones and their resolution is required before the mechanisms of resource allocation can usefully be considered.

\section{Alan Maynard}

The consequence of the ubiquitous problem of scarcity is that choices have to be made about which demands will be met and which will not-ie, which patients will benefit from care, and which patients will be denied care and be left in consequence either to live in pain or discomfort or, in some circumstances, to die? Who shall live and who shall die when health care resources are scarce? The central problem in the resource allocation debate-which non-economists call rationing-is what criteria should be used to allocate scarce resources amongst competing patients? Thus the purpose of this session is not to discuss whether to ration but how: what criteria should be used to determine which patients will be left to die and which patients will be left in pain and discomfort?

Those with a market (or liberal) ideology prefer to allocate resources in relation to willingness and ability to pay. Their idealised health care system works as follows: (a) individuals are the best judge of their own welfare; (b) priorities (who dies? who lives with what quality of life?) are determined by patients' (or their relatives') willingness and ability to pay; (c) the erratic and potentially catastrophic nature of demand is dealt with by private insurance; (d) distribution (equity) issues are to be dealt with by cash transfer via tax and social security. 
These arguments have been offered as a "solution" to the ineffectiveness and inequity of the NHS for decades. Such "ideals" do not work like this in the real world:

(a) Doctors act as patients' agents, determining the pattern of demand.

(b) Priorities are determined by the reimbursement rules of the insurers and by what takes the doctors' fancy!

(c) Risk rating and adverse selection distort individual willingness and ability to pay.

(d) Attempts to redistribute ability to pay are resisted because of its effect on incentives to work and take risks.

Those with a different ideology reject the market approach. The "ideal" NHS would have the following demand side characteristics: (a) individuals, when ill, are imperfect judges of their own welfare; (b) priorities would be determined by social judgements about need; (c) the erratic and catastrophic nature of health care demand is made irrelevant by provision of services free at the point of use; (d) with income and wealth distributed unequally, the NHS has to be protected from its effects.

However this "ideal" is not translated into practice: (a) doctors act as patients' agents, identifying need on their behalf; (b) priorities are determined by the doctors' professional environment, by "what is interesting" to them, by their assessment of patients' conditions and by their expectation of patients' capacity to cause trouble; (c) zero prices at the point of use enable patients to seek treatment for inappropriate conditions.

Such arguments are elaborated elsewhere. If we reject the principle of allocating resources according to willingness and ability to pay (but why is health care different from cars and cabbages? say Lees and Green), how can allocation according to need be operationalised?

Priorities have "to be determined by social judgements about need". At present allocations are determined largely by doctors and the basis of their choices is implicit, incoherent, and inconsistent. The economic approach to "unpacking" this covert process is to measure (guestimate?) the costs and outcomes of competing therapies in an explicit framework which is subject to debate and challenge. At its most provocative, and as an incentive to its opponents to do better (rather than throw the baby out with the bath water), it creates guestimate cost-outcome "league tables". Such information informs the rationing process based on need or benefit to patients, and would direct resources away from relatively cost ineffective (ie, high cost per quality adjusted life year [or QALY]) procedures such as liver transplants and breast cancer screening. Such choices are unavoidable and made every day in the NHS where patients are denied beneficial treatment because of resource constraints. The economic approach to rationing is explicit: it makes what is at present inconsistent, incoherent and implicit, open to democratic review.

This approach can be criticised easily: (a) the cost estimates are poor: who knows the price let alone the cost of anything in the NHS? (b) the survival data are poor: doctors and managers are often unable to identify hospital survival, let alone long term survival; (c) the quality of life (QoL) instruments are experimental, in need of replication and critical comparative review: QoL measurements are poor due to their long term neglect by researchers; (d) it is utilitarian (the greatest happiness of the greatest number).

Judgements have to be relative. Is the economic approach better than the alternatives? Is it better to challenge the implicit value judgements of doctors and reject alternative allocation rules such as drawing lots (what social support is there for such an allocation rule?), by using the economic approach to inform social choices about who will live and die? What is the alternative and does it give better social measures of need than the economic approach? From such comparisons the economic approach emerges as efficient, equitable, ethical and unavoidable.

\section{J. Grimley Evans}

One issue in contemporary debate is whether health service planning is to be concerned with improving health services from the consumer's or from the purveyor's point of view. It would be naive to deny that these aims may be incompatible. The traditional view is that a health service should be moulded by the demands and preferences of its customers. The purveyor's view, not substantiated empirically, is that this approach leads inevitably to excessive costs and not necessarily to services that reflect patients' best interests.

Measurement of the benefits of medical interventions, whether for clinical purposes or for health service planning, has long been dominated by survival times in one guise or another. For both epidemiological and ideological reasons we are now increasingly concerned with disability rather than with death, and this has lent allure to the QALY's promise of adding a non-disease-specific dimension of quality of survival to the appraisal of medical care. There are technical and philosophical problems which need to be resolved before it would be justifiable to institutionalise the QALY or any other measure of average outcomes in practical health service planning. Insofar as such a measure is to be used for choosing between two different treatments for the same disease in the same types of patients the problems are largely technical. The philosophical problems dominate if a measure of average outcome is used to decide, directly or indirectly, which patients are to be treated.

In forming decisions in the interest of the subjective wellbeing of individual patients, one set of technical problems arises from any conceptualisation of outcome as a single number purporting to reflect the subjective value of all the years of survival following medical intervention (or non-intervention). One objection to this model is that it may offer the patient inadequate scope for response to variance in the outcome itself. The prediction of survival and its quality are probabilistic, and in making a decision whether to undergo, say, a surgical operation, a patient might reasonably want to know the 
probability distribution and life quality of the whole range of possible outcomes, and not just some kind of mean value. Decision analysis studies have shown that individuals vary in their approach to uncertainty, and for the risk averse among us there might well be some outcomes that we would not be prepared to risk, even at low probability. A second problem lies in the management of interindividual variance. This is well exemplified in clinical practice among the elderly. On average, older surgical patients do less well than younger. The relevant causative variable is not age, however; it is the loss of physiological reserve which diminishes, but again only on average, with age. Elderly people who have preserved their phsyiological reserve do as well as younger patients. The use of average outcome of heterogeneous groups to determine the treatment of individuals is surely neither scientifically nor ideologically acceptable. Unfortunately, once allowed to happen it becomes difficult or impossible to carry out the research necessary to disaggregate the group.

From the consumer's point of view, clinical decisions should be based on the individual patient's value system, not on those of the doctor or administrator. It would be more convenient from the health service planners' point of view if norms could be established to which patients could be persuaded or required to conform. The compromise position would be for planning and audit at the "macro" level to be based on average outcomes but for the vagaries of patient choice to be respected and accommodated at the individual level. But if decisions about resource allocation are to be based on the evaluation of average outcomes, who is to do the evaluation? Some proponents of QALYs envisage quality of life estimates being set by the general public, a proposal that may seem reassuringly democratic. But we know that the quality of life associated with treatment may be more highly rated by patients with disease than by members of the healthy public, whose valuation is the more relevant to a democratic decision?

The issue is one of ideology. Part of the rationale for allowing health services to be determined by the purveyors (either the public that provides the funds or the Government that distributes them) rather than the customers, is the democratic assertion that all individuals are equal and therefore all person-years are equal. It therefore becomes justifiable, for example, to choose treatments and patients on the basis of maximising the numbers of QALYs purchased by the available health budget. This approach is ideologically flawed. Anglo-American democracy teaches not just that individuals are to be treated as equal, but that they are to be treated as equal because the worth of each individual is, in the strict sense of the word, infinite. "Infinite" in this context means "undefinable" and not necessarily "undefinably great".) It is not meaningful to manipulate infinity as if it were a finite number. The value of the life of an individual can be assessed only by that individual and not by his contribution to industrial output or his consumption of social security benefits. On this ideological basis the lives of different individuals are incommensurable and not made any less so by multiplying each by a QALY factor. Old Mrs A may value her remaining years of life more than young $\mathrm{Mr} B$ values his longer expectation but we can have no way of telling and it is ideologically mandatory that we accept that we never could.

The attraction for the politician of outcome measures such as the QALY is the prospect of turning difficult political decisions about the size and distribution of the health budget into routine technical procedures. This hope may be illusory. In choosing which patients should receive treatment the average outcome approach will, other things being equal, give preference to those with most years of remaining expectation of life to offer. Not only will this mean treating younger patients rather than older; it should also mean treating women rather than men, white patients rather than black, and upper social class patients rather than lower. One QALY enthusiast, acknowledging this difficulty, has suggested attaching varying weightings to the lives of members of different population groups. Politically, this could be at least as worrying as traditional ways of muddling through.

\section{John Harris}

As a discussant I shall have room to say something only briefly about each of the presentations in this symposium. Broadly speaking Professor Alwyn Smith and Professor John Grimley Evans recognise that there is an essentially political and maybe even moral dimension to the distribution of health care resources and both believe that this essentially political and moral element is inescapable and feeds into the raw material of choice. Professor Alan Maynard on the other hand believes that there is such a thing as raw data and that health economists such as himself are merely providing the tools whereby moral and political decisions may later be taken.

In his elegant introduction, ALWYN SMITH sees the essence of the debate as resolving "essentially into whether health and medical care should be used primarily to reduce health variance or to increase its mean. Is it to be viewed as contributing to the economic output of the nation or as part of the apparatus of social justice?" Now while I think that Smith is right to note the justice dimension of health care I have reservations about the way in which he seems to imply that the provision of health care services might be used, and indeed perhaps ought to be used, as a tool for achieving social justice. Should the health service or the allocation of resources to it be used specifically to reduce health variance-that is, to attempt to make all citizens equal with respect to the health that they enjoy? This is an interesting suggestion, but a startling one in that one way of achieving this objective might be to require a levelling down so that nobody should be unfairly advantaged in their enjoyment of health. Even if we stipulate that only levelling up will be countenanced, there are serious problems. For this would imply that we should arrive at some view as to what the highest level of health enjoyed is to be, and make no further improvements to people at this level of healthy existence while any who are below this 
level can have their health further improved. A practical consequence of such a policy might that we would not provide health care to those over a certain age, say three score and ten, until all the resources that might bring others up to this threshold had been exhausted.

Rather than thinking of the justice element in health care allocation as requiring that we use the resources in order to achieve social justice, we could regard the justice stipulation as applying to the way such resources are distributed. This might yield an imperative which for example required that each citizen were accorded the same concern, respect and protection as is accorded to any other in the allocation of health care resources. This would not necessarily reduce variance of course, but it would encapsulate at least one conception of justice.

JOHN GRIMLEY EVANS rightly identifies the basic problem posed by the use of economic measures of success in health care-and particularly those which depend upon a "life years adjusted for quality" approach as in the QALY favoured by Professor Maynard-as arising where such measures are used to decide "directly or indirectly which patients are to be treated". This is the crucial issue because the QALY inevitably dictates that treatment should be given first and foremost to those with the greater life expectancy and the better quality of life. In other words we should treat the fortunate first. Grimley Evans rightly demonstrates both the absurdity and the injustice of this. I deal only briefly with Grimley Evans' contribution because I largely agree with it.

ALAN MAYNARD puts the problem very bluntly. $\mathrm{He}$ insists that we are talking about "what criteria should be used to determine which patients will be left to die and which patients will be left in pain and discomfort?" When dealing with such a question he argues that "the economic approach is efficient, equitable, ethical and unavoidable". $\mathrm{He}$ points out, surely rightly, that if the alternative is just relying on the opinions or prejudices of doctors an objective and impartial measure would be attractive. But this is not the alternative we need recommend. He implies that by using the economic approach to reform social choices we will achieve justice; but the economic approach does not reform social choices, it dictates them. Once you have accepted that the QALY is "efficient, equitable, ethical and unavoidable", then you must implement the allocation that it dictates. And since this requires that in the allocation of scarce resources we prefer the healthy and potentially long lived to the unhealthy and potentially short lived, it denies what many have believed is a fundamental moral principle constraining all social and political choices in our society. That principle is that the lives of human persons are valuable in an ultimate sense. Whatever else this means, it means that all such lives are of equal value, and specifically that those with longer life expectancy or better quality are not for these reasons more valuable than others but that all must be treated equally in the allocation of scarce health resources.

Valuing life years, as Alan Maynard requires us to do, involves the idea that those with less life expectancy to gain from treatment (usually the old) are less worth saving than others. The same applies to those who are expensive to treat. By contrast, valuing the lives of all human persons equally requires both that we treat as many people as we can and that we ensure so far as is possible that certain sorts of people be not systematically ignored. Other things being equal, we should always rescue as many people as we can; but other things are not always equal. For example, other things being equal it will always be more expensive to treat people who live further from medical centres than those who live nearby. A QALY style expedient would simply involve ignoring the plight of "outlying" citizens. But a society which makes any claim to treating all its citizens as equals must make some provision for those who live in more remote parts of the country; and it must do this even at some increased cost. If it fails to do so it violates the equality principle. The same is true of many other areas of social provision. The handicapped may cost more to educate or to house, but a society which used that as a reason for ignoring their special needs would not be one which accorded them equality of concern and respect, and most would not think much of its claim to be a fair society either.

Now maybe our society, any society, ought (sometimes?) to violate this principle. Often more will simply count for more. But where this leads to systematic disadvantage to particular groupsthe poor, the old, the handicapped and so on - and particularly where such groups are also vulnerable or weak for other reasons, it will be unjust simply and always to go to the aid of the more fortunate majority. And this is what economic measures of efficiency in health care will require us to do. 